4

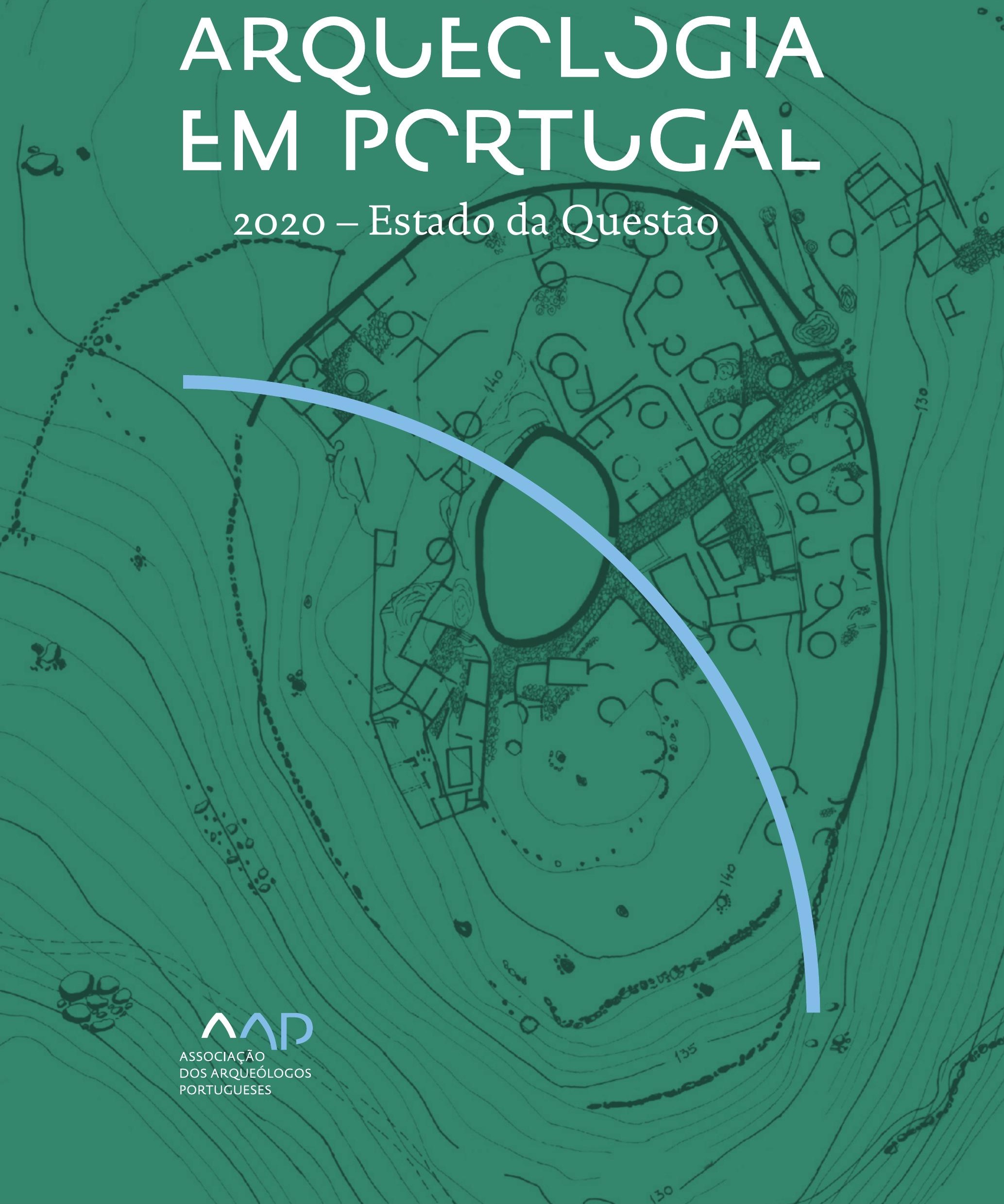


Coordenação editorial: José Morais Arnaud, César Neves e Andrea Martins Design gráfico: Flatland Design

AAP - ISBN: 978-972-9451-89-8

CITCEM - ISBN: 978-989-8970-25-1

Associação dos Arqueólogos Portugueses e CITCEM

Lisboa, 2020

O conteúdo dos artigos é da inteira responsabilidade dos autores. Sendo assim a Associação dos Arqueólogos Portugueses declina qualquer responsabilidade por eventuais equívocos ou questões de ordem ética e legal.

Desenho de capa:

Planta do castro de Monte Mozinho (Museu Municipal de Penafiel).

\section{$\hat{\wedge} \mathrm{P}$}

DOS ARQUEÓLOGOS PORTUGUESES

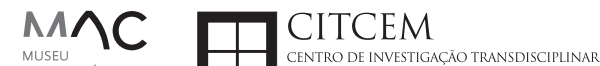
MUSEU
ARQUELLÓGICO
DO CARMO
U.PORTO

FLUP FACULDADE DE LETRAS
UNIVERSIDADE DO PORTO

Apoio

EC para a Ciência 


\section{Índice}

15 Prefácio

José Morais Arnaud

\section{Historiografia e Teoria}

17 Território, comunidade, memória e emoção: a contribuição da história da arqueologia (algumas primeiras e breves reflexões)

Ana Cristina Martins

25 Como descolonizar a arqueologia portuguesa?

Rui Gomes Coelho

41 Arqueologia e Modernidade: uma revisitação pessoal e breve de alguns aspetos da obra homónima de Julian Thomas de 2004

Vítor Oliveira Jorge

57 Dados para a História das Mulheres na Arqueologia portuguesa, dos finais do século XIX aos inícios do século XX: números, nomes e tabelas

Filipa Dimas / Mariana Diniz

73 Retractos da arqueologia portuguesa na imprensa: (in)visibilidades no feminino

Catarina Costeira / Elsa Luís

85 Arqueologia e Arqueólogos no Norte de Portugal Jacinta Bugalhão

101 Vieira Guimarães (1864-1939) e a arqueologia em Tomar: uma abordagem sobre o território e as gentes

João Amendoeira Peixoto / Ana Cristina Martins

115 Os memoráveis? A arqueologia algarvia na imprensa nacional e regional na presente centúria (2001-2019): características, visões do(s) passado(s) e a arqueologia

enquanto marca

Frederico Agosto / João Silva

129 A Evolução da Arqueologia Urbana e a Valorização Patrimonial no Barlavento Algarvio: Os casos de Portimão e Silves

Artur Mateus / Diogo Varandas / Rafael Boavida

\section{Gestão, Valorização e Salvaguarda do Património}

145 O Caderno Reivindicativo e as condições de trabalho em Arqueologia Miguel Rocha / Liliana Matias Carvalho / Regis Barbosa / Mauro Correia / Sara Simões / Jacinta Bugalhão / Sara Brito / Liliana Veríssimo Carvalho / Richard Peace / Pedro Peça / Cézer Santos

155 Os Estudos de Impacte Patrimonial como elemento para uma estratégia sustentável de minimização de impactes no âmbito de reconversões agrícolas Tiago do Pereiro

165 Salvaguarda de Património arqueológico em operações florestais: gestão e sensibilização Filipa Bragança / Gertrudes Zambujo / Sandra Lourenço / Belém Paiva / Carlos Banha / Frederico Tatá Regala / Helena Moura / Jacinta Bugalhão / João Marques / José Correia / Pedro Faria / Samuel Melro

179 Os valores do Património: uma investigação sobre os Sítios Pré-históricos de Arte Rupestre do Vale do Rio Côa e de Siega Verde José Paulo Francisco 
189 Conjugando recursos arqueológicos e naturais para potenciar as visitas ao Geoparque Litoral de Viana do Castelo (Noroeste de Portugal)

Hugo A. Sampaio / Ana M.S. Bettencourt / Susana Marinho / Ricardo Carvalhido

203 Áreas de Potencial Arqueológico na Região do Médio Tejo: Modelo Espacial Preditivo Rita Ferreira Anastácio / Ana Filipa Martins / Luiz Oosterbeek

223 Património Arqueológico e Gestão Territorial: O contributo da Arqueologia para a revisão do PDM de Avis

Ana Cristina Ribeiro

237 A coleção arqueológica do extinto Museu Municipal do Porto - Origens, Percursos e Estudos

Sónia Couto

251 Valpaços - uma nova carta arqueológica

Pedro Pereira / Maria de Fátima Casares Machado

263 Arqueologia na Cidade de Peniche

Adriano Constantino / Luís Rendeiro

273 Arqueologia Urbana: a cidade de Lagos como caso de Estudo Cátia Neto

285 Estratégias de promoção do património cultural subaquático nos Açores. O caso da ilha do Faial

José Luís Neto / José Bettencourt / Luís Borges / Pedro Parreira

297 Carta Arqueológica da Cidade Velha: Uma primeira abordagem

Jaylson Monteiro / Nireide Tavares / Sara da Veiga / Claudino Ramos / Edson Brito /

Carlos Carvalho / Francisco Moreira / Adalberto Tavares

311 Antropologia Virtual: novas metodologias para a análise morfológica e funcional Ricardo Miguel Godinho / Célia Gonçalves

\section{Didáctica da Arqueologia}

327 Como os projetos de Arqueologia podem contribuir para uma comunidade culturalmente mais consciente Alexandra Figueiredo / Claúdio Monteiro / Adolfo Silveira / Ricardo Lopes

337 Educação Patrimonial - Um cidadão esclarecido é um cidadão ativo! Ana Paula Almeida

351 A aproximação da Arqueologia à sala de aula: um caso de estudo no $3^{\circ}$ ciclo do Ensino Básico Luís Serrão Gil

363 Arqueologia 3.o - Pensar e comunicar a Arqueologia para um futuro sustentável Mónica Rolo

377 “Conversa de Arqueólogos" - Divulgar a Arqueologia em tempos de Pandemia Diogo Teixeira Dias

389 Escola Profissional de Arqueologia: desafios e oportunidades Susana Nunes / Dulcineia Pinto / Júlia Silva / Ana Mascarenhas

399 Os Museus de Arqueologia e os Jovens: a oferta educativa para o público adolescente Beatriz Correia Barata / Leonor Medeiros

411 O museu universitário como mediador entre a ciência e a sociedade: o exemplo da secção de arqueologia no Museu de História Natural e da Ciência da Universidade do Porto (MHNC-UP)

Rita Gaspar 
421 Museu de Lanifícios: Real Fábrica de Panos. Atividades no âmbito da Arqueologia Beatriz Correia Barata / Rita Salvado

427 Arqueologia Pública e o caso da localidade da Mata (Torres Novas) Cláudia Manso / Ana Rita Ferreira / Cristiana Ferreira / Vanessa Cardoso Antunes

431 Do sítio arqueológico ao museu: um percurso (também) didático Lídia Fernandes

447 Estão todos convidados para a Festa! E para dançar também... O projecto do Serviço Educativo do Museu Arqueológico do Carmo na $5^{\underline{a}}$ Edição da Festa da Arqueologia Rita Pires dos Santos

459 O “Clã de Carenque”, um projeto didático de arqueologia Eduardo Gonzalez Rocha

469 Mediação cultural: peixe que puxa carroça nas Ruínas Romanas de Troia Inês Vaz Pinto / Ana Patrícia Magalhães / Patrícia Brum / Filipa Santos

481 Didática Arqueológica, experiências do Projeto Mértola Vila Museu Maria de Fátima Palma / Clara Rodrigues / Susana Gómez / Lígia Rafael

\section{Arte Rupestre}

497 Os inventários de arte rupestre em Portugal Mila Simões de Abreu

513 O projeto FIRST-ART - conservação, documentação e gestão das primeiras manifestações de arte rupestre no Sudoeste da Península Ibérica: as grutas do Escoural e Maltravieso Sara Garcês / Hipólito Collado / José Julio García Arranz / Luiz Oosterbeek / António Carlos Silva / Pierluigi Rosina / Hugo Gomes / Anabela Borralheiro Pereira / George Nash / Esmeralda Gomes / Nelson Almeida / Carlos Carpetudo

523 Trabalhos de documentação de arte paleolítica realizados no âmbito do projeto PalæoCôa André Tomás Santos / António Fernando Barbosa / Luís Luís / Marcelo Silvestre / Thierry Aubry

537 Imagens fantasmagóricas, silhuetas elusivas: as figuras humanas na arte do Paleolítico Superior da região do Côa Mário Reis

$55^{1}$ Os motivos zoomórficos representados nas placas de tear de Vila Nova de São Pedro (Azambuja, Portugal) Andrea Martins / César Neves / José M. Arnaud / Mariana Diniz

571 Arte Rupestre do Monte de Góios (Lanhelas, Caminha). Síntese dos resultados dos trabalhos efectuados em 2007-2009 Mário Varela Gomes

599 Gravuras rupestres de barquiformes no Monte de S. Romão, Guimarães, Noroeste de Portugal Daniela Cardoso

613 Círculos segmentados gravados na Bacia do Rio Lima (Noroeste de Portugal): contributos para o seu estudo Diogo Marinho / Ana M.S. Bettencourt / Hugo Aluai Sampaio

631 Equídeos gravados no curso inferior do Rio Mouro, Monção (NW Portugal). Análise preliminar Coutinho, L.M. / Bettencourt, A.M.S / Sampaio, Hugo A.S

645 Paletas na Arte Rupestre do Noroeste de Portugal. Inventário preliminar Bruna Sousa Afonso / Ana M. S. Bettencourt / Hugo A. Sampaio 


\section{Pré-História}

661 O projeto Miño/Minho: balanço de quatro anos de trabalhos arqueológicos Sérgio Monteiro-Rodrigues / João Pedro Cunha-Ribeiro / Eduardo Méndez-Quintas / Carlos Ferreira / Pedro Xavier / José Meireles / Alberto Gomes / Manuel Santonja / Alfredo Pérez-González

677 A ocupação paleolítica da margem esquerda do Baixo Minho: a indústria lítica do sítio de Pedreiras 2 (Monção, Portugal) e a sua integração no contexto regional Carlos Ferreira / João Pedro Cunha-Ribeiro / Sérgio Monteiro-Rodrigues / Eduardo Méndez-Quintas / Pedro Xavier / José Meireles / Alberto Gomes / Manuel Santonja / Alfredo Pérez-González

693 O sítio acheulense do Plistocénico médio da Gruta da Aroeira Joan Daura / Montserrat Sanz / Filipa Rodrigues / Pedro Souto / João Zilhão

703 As sociedades neandertais no Barlavento algarvio: modelos preditivos com recurso aos SIG

Daniela Maio

715 A utilização de quartzo durante o Paleolítico Superior no território dos vales dos rios Vouga e Côa

Cristina Gameiro / Thierry Aubry / Bárbara Costa / Sérgio Gomes / Luís Luís / Carmen Manzano / André Tomás Santos

733 Uma perspetiva diacrónica da ocupação do concheiro do Cabeço da Amoreira (Muge, Portugal) a partir da tecnologia lítica Joana Belmiro / João Cascalheira / Célia Gonçalves

745 Novos dados sobre a Pré-história Antiga no concelho de Palmela. A intervenção arqueológica no sítio do Poceirão I

Michelle Teixeira Santos

757 Problemas em torno de Datas Absolutas Pré-Históricas no Norte do Alentejo Jorge de Oliveira

771 Povoamento pré-histórico nas áreas montanhosas do NO de Portugal: o Abrigo 1 de Vale de Cerdeira Pedro Xavier / José Meireles / Carlos Alves

783 Apreciação do povoamento do Neolítico Inicial na Baixa Bacia do Douro. A Lavra I (Serra da Aboboreira) como caso de estudo Maria de Jesus Sanches

797 O Processo de Neolitização na Plataforma do Mondego: os dados do Sector C do Outeiro dos Castelos de Beijós (Carregal do Sal)

João Carlos de Senna-Martinez / José Manuel Quintã Ventura / Andreia Carvalho / Cíntia Maurício

823 Novos trabalhos na Lapa da Bugalheira (Almonda, Torres Novas) Filipa Rodrigues / Pedro Souto / Artur Ferreira / Alexandre Varanda / Luís Gomes / Helena Gomes / João Zilhão

837 A pedra polida e afeiçoada do sítio do Neolítico médio da Moita do Ourives (Benavente, Portugal)

César Neves

857 Casal do Outeiro (Encarnação, Mafra): novos contributos para o conhecimento do povoamento do Neolítico final na Península de Lisboa.

Cátia Delicado / Carlos Maneira e Costa / Marta Miranda / Ana Catarina Sousa

873 Stresse infantil, morbilidade e mortalidade no sítio arqueológico do Neolítico Final/ Calcolítico ( $4^{\circ}$ e $3^{\circ}$ milénio a.C.) do Monte do Carrascal 2 (Ferreira do Alentejo, Beja) Liliana Matias de Carvalho / Sofia N. Wasterlain 
885 Come together: O Conjunto Megalítico das Motas (Monção, Viana do Castelo) e as expressões Campaniformes do Alto Minho Ana Catarina Basílio / Rui Ramos

899 Trabalhos arqueológicos no sítio Calcolítico da Pedreira do Poio Carla Magalhães / João Muralha / Mário Reis / António Batarda Fernandes

913 O sítio arqueológico de Castanheiro do Vento. Da arquitectura do sítio à arquitectura de um território João Muralha Cardoso

925 Estudo zooarqueológico das faunas do Calcolítico final de Vila Nova de São Pedro (Azambuja, Portugal): Campanhas de 2017 e 2018 Cleia Detry / Ana Catarina Francisco / Mariana Diniz / Andrea Martins / César Neves / José Morais Arnaud

943 As faunas depositadas no Museu Arqueológico do Carmo provenientes de Vila Nova de São Pedro (Azambuja): as campanhas de 1937 a 1967 Ana Catarina Francisco / Cleia Detry / César Neves / Andrea Martins / Mariana Diniz / José Morais Arnaud

959 Análise funcional de material lítico em sílex do castro de Vila Nova de S. Pedro (Azambuja, Portugal): uma primeira abordagem Rafael Lima

971 O recinto da Folha do Ouro 1 (Serpa) no contexto dos recintos de fossos calcolíticos alentejanos

António Carlos Valera / Tiago do Pereiro / Pedro Valério / António M. Monge Soares

\section{Proto-História}

987 Produção de sal marinho na Idade do Bronze do noroeste Português. Alguns dados para uma reflexão

Ana M. S. Bettencourt / Sara Luz / Nuno Oliveira / Pedro P. Simões / Maria Isabel C. Alves / Emílio Abad-Vidal

1001 A estátua-menir do Pedrão ou de São Bartolomeu do Mar (Esposende, noroeste de Portugal) no contexto arqueológico da fachada costeira de entre os rios Neiva e Cávado Ana M. S. Bettencourt / Manuel Santos-Estévez / Pedro Pimenta Simões / Luís Gonçalves

1015 O Castro do Muro (Vandoma/Baltar, Paredes) - notas para uma biografia de ocupação da Idade do Bronze à Idade Média

Maria Antónia D. Silva / Ana M. S. Bettencourt / António Manuel S. P. Silva / Natália Félix

1031 Do Bronze Final à Idade Média - continuidades e hiatos na ocupação de Povoados em Oliveira de Azeméis João Tiago Tavares / Adriaan de Man

1041 As faunas do final da Idade do Bronze no Sul de Portugal: leituras desde o Outeiro do Circo (Beja)

Nelson J. Almeida / Íris Dias / Cleia Detry / Eduardo Porfírio / Miguel Serra

1055 A Espada do Monte das Oliveiras (Serpa) - uma arma do Bronze Pleno do Sudoeste Rui M. G. Monge Soares / Pedro Valério / Mariana Nabais / António M. Monge Soares

1065 São Julião da Branca (Albergaria-a-Velha) - Investigação e valorização de um povoado do Bronze Final

António Manuel S. P. Silva / Paulo A. P. Lemos / Sara Almeida e Silva / Edite Martins de Sá

1083 Do castro de S. João ao Mosteiro de Santa Clara: notícia de uma intervenção arqueológica, em Vila do Conde Rui Pinheiro 
1095 O castro de Ovil (Espinho), um quarto de século de investigação - resultados e questões em aberto

Jorge Fernando Salvador / António Manuel S. P. Silva

1111 O Castro de Salreu (Estarreja), um povoado proto-histórico no litoral do Entre Douro e Vouga

Sara Almeida e Silva / António Manuel S. P. Silva / Paulo A. P. Lemos / Edite Martins de Sá

1127 Castro de Nossa Senhora das Necessidades (Sernancelhe): uma primeira análise artefactual Telma Susana O. Ribeiro

${ }_{1141}$ A cividade de Bagunte. O estado atual da investigação Pedro Brochado de Almeida

1153 Zoomorfos na cerâmica da Idade do Ferro no NW Peninsular: inventário, cronologias e significado Nuno Oliveira / Cristina Seoane

1163 Vasos gregos em Portugal: diferentes maneiras de contar a história do intercâmbio cultural na Idade do Ferro

Daniela Ferreira

1175 Os exotica da necrópole da Idade do Ferro do Olival do Senhor dos Mártires (Alcácer do Sal) no seu contexto regional

Francisco B. Gomes

\section{Antiguidade Clássica e Tardia}

1191 O uso de madeira como combustível no sítio da Quinta de Crestelos (Baixo Sabor): da Idade do Ferro à Romanização Filipe Vaz / João Tereso / Sérgio Simões Pereira / José Sastre / Javier Larrazabal Galarza / Susana Cosme / José António Pereira / Israel Espi

1207 Cultivos de Época Romana no Baixo Sabor: continuidade em tempos de mudança? João Pedro Tereso / Sérgio Simões Pereira / Filipe Santos / Luís Seabra / Filipe Vaz

1221 A casa romana na Hispânia: aplicação dos modelos itálicos nas províncias ibéricas Fernanda Magalhães / Diego Machado / Manuela Martins

1235 As pinturas murais romanas da Rua General Sousa Machado, n. ${ }^{5}$ 1, Chaves José Carvalho

1243 Trás do Castelo (Vale de Mir, Pegarinhos, Alijó) - Uma exploração agrícola romana do Douro

Tony Silvino / Pedro Pereira

1255 A sequência de ocupação no quadrante sudeste de Bracara Augusta: as transformações de uma unidade doméstica Lara Fernandes / Manuela Martins

1263 Os Mosaicos com decoração geométrica e geométrico-vegetalista dos sítios arqueológicos da área do Conuentus Bracaraugustanus. Novas abordagens quanto à conservação, restauro, decoração e datação Maria de Fátima Abraços / Licínia Wrench

1277 “Casa Romana” do Castro de São Domingos (Cristelos, Lousada): Escavação, Estudo e Musealização Paulo André de P. Lemos

1291 A arqueobotânica no Castro de Guifões (Matosinhos, Noroeste de Portugal): O primeiro estudo carpológico

Luís Seabra / Andreia Arezes / Catarina Magalhães / José Varela / João Pedro Tereso 
1305 Um Horreum Augustano na Foz do Douro (Monte do Castelo de Gaia, Vila Nova de Gaia) Rui Ramos

1311 Ponderais romanos na Lusitânia: padrões, formas, materiais e contextos de utilização Diego Barrios Rodríguez

1323 Um almofariz centro-itálico na foz do Mondego

Marco Penajoia

1335 Estruturas romanas de Carnide - Lisboa Luísa Batalha / Mário Monteiro / Guilherme Cardoso

1347 O contexto funerário do sector da "necrópole NO" da Rua das Portas de S. Antão (Lisboa): o espaço, os artefactos, os indivíduos e a sua interconectividade na interpretação do passado Sílvia Loja, José Carlos Quaresma, Nelson Cabaço, Marina Lourenço, Sílvia Casimiro, Rodrigo Banha da Silva, Francisca Alves-Cardoso

${ }_{1361}$ Povoamento em época Romana na Amadora - resultados de um projeto pluridisciplinar Gisela Encarnação / Vanessa Dias

1371 A Arquitectura Residencial em Mirobriga (Santiago do Cacém): contributo a partir de um estudo de caso Filipe Sousa / Catarina Felício

${ }_{1385}$ O fim do ciclo. Saneamento e gestão de resíduos nos edifícios termais de Mirobriga (Santiago do Cacém)

Catarina Felício / Filipe Sousa

1399 Balsa, Topografia e Urbanismo de uma Cidade Portuária Vítor Silva Dias / João Pedro Bernardes / Celso Candeias / Cristina Tété Garcia

1413 No Largo das Mouras Velhas em Faro (2017): novas evidências da necrópole norte de Ossonoba e da sua ocupação medieval Ricardo Costeira da Silva / Paulo Botelho / Fernando Santos / Liliana Nunes

1429 Instrumentos de pesca recuperados numa fábrica de salga em Ossonoba (Faro) Inês Rasteiro / Ricardo Costeira da Silva / Paulo Botelho

1439 A Necrópole Romana do Eirô, Duas Igrejas (Penafiel): intervenção arqueológica de 2016 Laura Sousa / Teresa Soeiro

1457 Ritual, descarte ou afetividade? A presença de Canis lupus familiaris na Necrópole Noroeste de Olisipo (Lisboa)

Beatriz Calapez Santos / Sofia Simões Pereira / Rodrigo Banha da Silva / Sílvia Casimiro / Cleia Detry / Francisca Alves Cardoso

1467 Dinâmicas económicas em Bracara na Antiguidade Tardia Diego Machado / Manuela Martins / Fernanda Magalhães / Natália Botica

1479 Cerâmicas e Vidros da Antiguidade Tardia do Edifício sob a Igreja do Bom Jesus (Vila Nova de Gaia) Joaquim Filipe Ramos

1493 Novos contributos para a topografia histórica de Mértola no período romano e na Antiguidade Tardia Virgílio Lopes

\section{8. Época Medieval}

1511 Cerâmicas islâmicas no Garb setentrional "português": algumas evidências e incógnitas Constança dos Santos / Helena Catarino / Susana Gómez / Maria José Gonçalves / Isabel Inácio / Gonçalo Lopes / Jacinta Bugalhão / Sandra Cavaco / Jaquelina Covaneiro / Isabel Cristina Fernandes / Ana Sofia Gomes 
1525 Contributo para o conhecimento da cosmética islâmica, em Silves, durante a Idade Média Rosa Varela Gomes

1537 Yábura e o seu território - uma análise histórico-arqueológica de Évora entre os séculos VIII-XII José Rui Santos

1547 A encosta sul do Castelo de Palmela - resultados preliminares da escavação arqueológica Luís Filipe Pereira / Michelle Teixeira Santos

1559 A igreja de São Lourenço (Mouraria, Lisboa): um conjunto de silos e de cerâmica medieval islâmica

Andreia Filipa Moreira Rodrigues

1571 O registo material de movimentações populacionais no Médio Tejo, durante os séculos XII-XIII. Dois casos de "sunken featured buildings", nos concelhos de Cartaxo e Torres Novas Marco Liberato / Helena Santos / Nuno Santos

1585 O nordeste transmontano nos alvores da Idade média. Notas para reflexão Ana Maria da Costa Oliveira

1601 Sepulturas escavadas na rocha do Norte de Portugal e do Vale do Douro: primeiros resultados do Projecto SER-NPVD

Mário Jorge Barroca / César Guedes / Andreia Arezes / Ana Maria Oliveira

1619 "Portucalem Castrum Novum" entre o Mediterrâneo e o Atlântico: o estudo dos materiais cerâmicos alto-medievais do arqueossítio da rua de D. Hugo, nํ. 5 (Porto) João Luís Veloso

1627 A Alta Idade Média na fronteira de Lafões: notas preliminares sobre a Arqueologia no Concelho de Vouzela

Manuel Luís Real / Catarina Tente

1641 Um conjunto cerâmico medieval fora de portas: um breve testemunho aveirense Susana Temudo

${ }_{1651}$ Os Lóios do Porto: uma perspetiva integrada no panorama funerário da Baixa Idade Média à Época Moderna em meios urbanos em Portugal

Ana Lema Seabra

1659 O Caminho Português Interior de Santiago como eixo viário na Idade Média Pedro Azevedo

1665 Morfologia Urbana: Um exercício em torno do Castelo de Ourém André Donas-Botto / Jaqueline Pereira

1677 Intervenção arqueológica na Rua Marquês de Pombal/Largo do Espírito Santo (Bucelas, Loures)

Florbela Estêvão / Nathalie Antunes-Ferreira / Dário Ramos Neves / Inês Lisboa

1691 O Cemitério Medieval do Poço do Borratém e a espacialidade funerária na cidade de Lisboa Inês Belém / Vanessa Filipe / Vasco Noronha Vieira / Sónia Ferro / Rodrigo Banha da Silva

1705 Um Espaço Funerário Conventual do séc. XV em Lisboa: o caso do Convento de São Domingos da Cidade Sérgio Pedroso / Sílvia Casimiro / Rodrigo Banha da Silva / Francisca Alves Cardoso

\section{9. Época Moderna e Contemporânea}

1721 Arqueologia Moderna em Portugal: algumas reflexões críticas em torno da quantificação de conjuntos cerâmicos e suas inferências históricas e antropológicas Rodrigo Banha da Silva / André Bargão / Sara da Cruz Ferreira

1733 Faianças de dois contextos entre os finais do século XVI e XVIII do Palácio dos Condes de Penafiel, Lisboa

Martim Lopes / Tomás Mesquita 
1747 Um perfil de consumo do século XVIII na foz do Tejo: O caso do Mercado da Ribeira, Lisboa Sara da Cruz Ferreira / Rodrigo Banha da Silva / André Bargão

1761 Os Cachimbos dos Séculos XVII e XVIII do Palácio Mesquitela e Convento dos Inglesinhos (Lisboa)

Inês Simão / Marina Pinto / João Pimenta / Sara da Cruz Ferreira / André Bargão / Rodrigo Banha da Silva

1775 "Tomar os fumos da erua que chamão em Portugal erua sancta». Estudo de Cachimbos provenientes da Rua do Terreiro do Trigo, Lisboa

Miguel Martins de Sousa / José Pedro Henriques / Vanessa Galiza Filipe

1787 Cachimbos de Barro Caulínitico da Sé da Cidade Velha (República de Cabo Verde)

Rodrigo Banha da Silva / João Pimenta / Clementino Amaro

1801 Algumas considerações sobre espólio não cerâmico recuperado no Largo de Jesus (Lisboa) Carlos Boavida

1815 Adereços de vidro, dos séculos XVI-XVIII, procedentes do antigo Convento de Santana de Lisboa (anéis, braceletes e contas)

Joana Gonçalves / Rosa Varela Gomes / Mário Varela Gomes

1837 Da ostentação, luxo e poder à simplicidade do uso quotidiano: arqueologia e simbologia de joias e adornos da Idade Moderna Portuguesa Jéssica Iglésias

1849 Os amuletos em Portugal - dos objetos às superstições: o coral vermelho Alexandra Vieira

1865 Cerâmicas de Vila Franca de Xira nos séculos XV e XVI Eva Pires

1879 «Não passa por teu o que me pertence». Marcas de individualização associadas a faianças do Convento de Nossa Senhora de Aracoeli, Alcácer do Sal Catarina Parreira / Íris Fragoso / Miguel Martins de Sousa

1891 Cerâmica de Leiria: alguns focos de produção

Jaqueline Pereira / André Donas-Botto

1901 Os Fornos na Rua da Biquinha, em Óbidos Hugo Silva / Filipe Oliveira

1909 A casa de Pêro Fernandes, contador dos contos de D. Manuel I: o sítio arqueológico da Silha do Alferes, Seixal (século XVI) Mariana Nunes Ferreira

1921 O Alto da Vigia (Sintra) e a vigilância e defesa da costa Alexandre Gonçalves / Sandra Santos

1937 O contexto da torre sineira da Igreja de Santa Maria de Loures Paulo Calaveira / Martim Lopes

1949 A Necrópole do Hospital Militar do Castelo de São Jorge e as práticas funerárias na Lisboa de Época Moderna Susana Henriques / Liliana Matias de Carvalho / Ana Amarante / Sofia N. Wasterlain

1963 SAND - Sarilhos Grandes Entre dois Mundos: o adro da Igreja e a Paleobiologia dos ossos humanos recuperados

Paula Alves Pereira / Roger Lee Jesus / Bruno M. Magalhães

1975 Expansão urbana da vila de Cascais no século XVII e XVIII: a intervenção arqueológica na Rua da Vitória no 15 a 17

Tiago Pereira / Vanessa Filipe

1987 Novos dados para o conhecimento do Urbanismo de Faro em época Moderna Ana Rosa 
1995 Um exemplo de Arqueologia Urbana em Alcoutim: o Antigo Edifício dos CTT Marco Fernandes / Marta Dias / Alexandra Gradim / Virgílio Lopes / Susana Gómez Martínez

2007 Palácio dos Ferrazes (Rua das Flores/Rua da Vitória, Porto): a cocheira de Domingos Oliveira Maia

Francisco Raimundo

2021 As muitas vidas de um edifício urbano: História, Arqueologia e Antropologia no antigo Recreatório Paroquial de Penafiel Helena Bernardo / Jorge Sampaio / Marta Borges

2035 O convento de Nossa Senhora da Esperança de Ponta Delgada: o contributo da arqueologia para o conhecimento de um monumento identitário João Gonçalves Araújo / N’Zinga Oliveira

2047 Arqueologia na ilha do Corvo... em busca da capela de Nossa Senhora do Rosário Tânia Manuel Casimiro / José Luís Neto / Luís Borges / Pedro Parreira

2059 Perdidos à vista da Costa. Trabalhos arqueológicos subaquáticos na Barra do Tejo Jorge Freire / José Bettencourt / Augusto Salgado

2071 Arqueologia marítima em Cabo Verde: enquadramento e primeiros resultados do projecto CONCHA

José Bettencourt / Adilson Dias / Carlos Lima / Christelle Chouzenoux / Cristóvão Fonseca / Dúnia Pereira / Gonçalo Lopes / Inês Coelho / Jaylson Monteiro / José Lima / Maria Eugénia Alves / Patrícia Carvalho / Tiago Silva

2085 Trabalhos arqueológicos na Cidade Velha (Ribeira Grande de Santiago, Cabo Verde): reflexões sobre um projecto de investigação e divulgação patrimonial André Teixeira / Jaylson Monteiro / Mariana Mateus / Nireide Tavares / Cristovão Fonseca / Gonçalo C. Lopes / Joana Bento Torres / Dúnia Pereira / André Bargão / Aurélie Mayer / Bruno Zélie / Carlos Lima / Christelle Chouzenoux / Inês Henriques / Inês Pinto Coelho / José Lima / Patrícia Carvalho / Tiago Silva

2103 A antiga fortificação de Quelba / Khor Kalba (E.A.U.). Resultados de quatro campanhas de escavações, problemáticas e perspectivas futuras Rui Carita / Rosa Varela Gomes / Mário Varela Gomes / Kamyar Kamyad

2123 Colónias para homens novos: arqueologia da colonização agrária fascista no noroeste ibérico Xurxo Ayán Vila / José Mạ . Señorán Martín 


\title{
«NÃO PASSA POR TEU O QUE ME PERTENCE॥. MARCAS DE INDIVIDUALIZA- ÇÃO ASSOCIADAS A FAIANÇAS DO CONVENTO DE NOSSA SENHORA DE ARACOELI, ALCÁCER DO SAL
}

\author{
Catarina Parreira ${ }^{1}$, Íris Fragoso ${ }^{2}$, Miguel Martins de Sousa ${ }^{3}$
}

\begin{abstract}
RESUMO
Fundado em 1573 por Rui Salema e Catarina Sotto Mayor Salema, o Convento de Nossa Senhora de Aracoeli, instalou-se nos antigos paços mestrais da Ordem de Santiago. Extinto em 1874, foi-se degradando até à requalificação em Pousada D. Afonso II. Na sequência das campanhas arqueológicas realizadas entre 1993 e 1997, identificou-se expressivo espólio do qual se destaca uma ampla coleção de faiança portuguesa de diversas tipologias e cronologias.

A problemática que se apresenta relaciona-se com motivos incisos que o estudo das faianças, recolhidas em duas áreas da cerca conventual, proporcionou. Assim, a análise aferida utiliza o espólio como indicador socioeconómico, levando à inserção do conjunto de faianças no quotidiano conventual, quiçá profilático, de Alcácer do Sal. Palavras-chave: Cultura Material, Idade Moderna, Marcas incisas, Alcácer do Sal, Faiança Portuguesa.
\end{abstract}

\begin{abstract}
Founded in 1573 by Rui Salema and Catarina Sotto Mayor Salema, the Convento de Nossa Senhora de Aracoeli was located in the old house of the Order of Santiago. Extinct in 1874 it was in ruins by the renovation undertaken for the building of Pousada D. Afonso II. Following the excavation, carried out between 1993 and 1997, expressive archaeological remains were identified, including a diverse collection of Portuguese faience.

The issue that is presented relates to incised motifs which the study of the faience, collected in two sites from the conventual fence, reveled. Therefore, this study uses a selected assemblage as a socioeconomic indicator, leading it to be associated with the conventual, perhaps prophylactic, daily routine of Alcácer do Sal.

Keywords: Material culture, Early modern age, Incised marks, Alcácer do Sal, Portuguese faience.
\end{abstract}

\section{INTRODUÇÃO}

Com o objetivo de reverter o estado de degradação do Castelo de Alcácer do Sal, nos anos 90 avançou-se com um projeto de remodelação no espaço do antigo convento tendo em vista torná-lo numa pou- sada. A ação arqueológica, com início em 1993, assumiu o carácter de uma intervenção de emergência. Incidindo na área do edifício religioso, as campanhas foram programadas proporcionando a identificação de estruturas que permitissem, simultaneamente, fornecer maior informação histórico-arqueológica

\footnotetext{
1. Mestre em Arqueologia pela Faculdade de Ciências Sociais e Humanas da Universidade Nova de Lisboa, Avenida de Berna, 26-C, 1069-061 Lisboa; catarinaparreira@live.com.pt

2. Mestre em Arqueologia pela Faculdade de Ciências Sociais e Humanas da Universidade Nova de Lisboa, Avenida de Berna, 26-C, 1069-061 Lisboa; irisfragoso@live.com.pt

3. Mestre em Arqueologia pela Faculdade de Ciências Sociais e Humanas da Universidade Nova de Lisboa, Avenida de Berna, 26-C, 1069-061 Lisboa; miguelmsousa1996@gmail.com
} 
e delegando aos técnicos responsáveis pelas obras de adaptação do monumento a pousada, elementos úteis que pudessem contribuir para a valorização do edifício (Paixão; Faria, 1996, p. s. n..o).

$\mathrm{Na}$ aferição de estudos relativos a marcas incisas, em particular em faiança, este revelou-se parcamente desenvolvido no panorama científico nacional. A sua apresentação é meramente descritiva (Amaro \& alii, 2016, p. 71, 75; Almeida; Fernandes; Cândido, 2016, p. 154), estando em falta um esclarecimento para a necessidade da execução das mesmas. O mote que desencadeia este artigo, nomeadamente "Não passa por teu o que me pertence", sugere assim a consideração levada a cabo por quem pretendia demarcar uma ou um conjunto de peças indicando uma finalidade específica. Num difuso grupo de finalidades, as marcas exibem-se nos dias de hoje como testemunhos essenciais para que se possa, mesmo de forma subjetiva, alcançar uma interpretação possível.

Procuramos, deste modo, através da análise de parte de um diversificado conjunto de faiança portuguesa, apresentar um dos elementos mais insólitos das mesmas. As marcas incisas podem, assim, revelar detalhes da caracterização socioeconómica dos fácies cerâmicos portugueses provenientes do Convento de Nossa Senhora de Aracoeli.

\section{ELEMENTOS DE CONTEXTUALIZAÇÃO HISTÓRICA DO CONVENTO DE NOSSA SENHORA DE ARACOELI}

Aquando da degradação do edifício que albergava a sede mestral da Ordem de Santiago de Espada, do qual fez parte o convento espatário e os paços santiaguistas, após a sua transferência para Palmela no ano de 1482 , este é retratado na visitação de $1534^{4}$, onde se anuncia que "as casas do castelo desta villa estam muito danificadas desta maneira que não tem nenhuas portas nem genellas e homde nos portaes avia umbrejras de pedrarja leuadas que não ficam se não as traves tee as chumjnees derrybadas o de dentro e leuados os tijolos dellas" (Pereira, 2015, p. 223). Rui Salema ${ }^{5}$ e Dona Catarina Sotto Mayor Salema

\footnotetext{
4. Visitações a Alcácer do Sal efetuadas pelo Mestre D. Jorge, Álvaro Mendes, Cavaleiro da Ordem de Santiago, e Afonso Henriques, Prior da Igreja de São Pedro de Palmela, visitadores da Comarca de Campo de Ourique.

5. Criado do Infante Luís e comendador de Cristo em 1530 (Correia, 1972, p. 146; Leal, 1873, p. 58).
}

requerem a doação dos "Paços Velhos" da Ordem de Santiago com a sua cerca, torres e quinta, existentes dentro do castelo, com a pretensão de fundar um convento franciscano feminino (Fig.1), da Ordem de Santa Clara, na segunda metade do século XVI, que dotariam com bens para a respetiva manutenção e sustento. Através do Arquivo Gama Lobo Salema é possível aferir que o casal não teve descendência, talvez por isso tivesse o desejo de fundar o convento. Neste sentido, estariam a partilhar parte dos seus bens para uma causa que seria espiritualmente tranquilizadora na qual buscavam a intercessão do divino (Pereira, 2015, p. 223; Andrade, 2011, p. 172), numa lógica de devoção que se prende com as distâncias não apenas de âmbito cronológico, mas também culturais e sociais, que nos separam das mentalidades do século XVI.

Em 1561 é outorgado um breve do legado apostólico que concede a licença para a edificação do convento, numa comissão enviada por D. Sebastião, onde se revelam as condições necessárias para que este convento fosse edificado. Deste modo, a sua (re)construção traria nova vida àquele espaço que se encontrava em ruínas, para o qual era doada a Quinta de Arapouco que incluía outras propriedades e três moinhos, pomares, olivais e vinhas, o que "era boa renda e dote conveniente" para o dito convento (AHMALCS, oo5, f.3). Caso este deixasse de existir ou mudasse para outro local, todos os bens seriam transferidos para a Santa Casa da Misericórdia de Alcácer do Sal, de quem eram também mecenas, nunca se podendo vender ou doar a Quinta e os seus bens pertencentes (Pereira, 2015, p. 224; AHMALCS, oo5, f.3).

Da residência espatária que por ordem do segundo mestre D. Lourenço Anes se começou a edificar em fins do século XIII pouco restou, segundo Virgílio Correia (1972, p. 138), "as concessões de pedra para a construção e desenvolvimento do convento fizeram obliterar a sua memória”. No entanto, os princípios aplicados para a implantação do convento pouco diferem dos que foram essenciais para a do castelo islâmico aprofundado noutros trabalhos (Leitão, 2015). A proximidade de vias de comunicação, quer terrestres, quer fluviais, a proximidade de um cenóbio masculino, nomeadamente o Convento de Santo António, em que os frades se encarregam de zelar pelo cumprimento e observância da vida religiosa interna e também pela organização social e económica, bem como a sua localização nas imediações 
da urbe são elementos que justificam a sua escolha, como ao longo dos tempos foi ocorrendo (Andrade, 2011, p. 132, 413).

Podemos verificar ainda que existem diferentes tipos de soluções construtivas, mostrando que o convento não foi edificado de raiz, mas que aproveitou uma série de estruturas pré-existentes no local pertencentes a outros edifícios, como é o exemplo da alcáçova muçulmana e do Paço Real da Ordem de Santiago (Leitão, 2015, p. 47). Assim, o convento era delimitado a norte, poente e sul pelas muralhas do castelo e a nascente com o caminho que ia para o postigo e com outro que seguia para a Porta Nova sendo inaugurado, nesta configuração, a 3 de junho de 1573 (Pereira, 2015, p. 225).

Mais tarde, numa petição datada de 1792, a Abadessa Maria da Conceição revelava a D. Maria I o reduzido número de 13 religiosas que se encontravam no convento, muito longe do número designado de 33 na sua fundação. A abadessa descreve-as ainda como doentes e decrépitas, não podendo estas satisfazer ao ofício divino no coro e às necessárias obrigações da comunidade. Referia que desde 1755 que não entravam ali noviças, ao contrário e a "favor" do que acontecia noutras casas religiosas, imputando sua majestade pela possibilidade de extinção desta comunidade. A suplicante pleiteia a que se conceda licença para aceitar 12 noviças passando o seu número para 25 (ANTT, N. 54). Sabe-se também que após um período de paz o convento é notícia por albergar os oficiais de guarnições militares, tanto liberais como miguelistas, em tempos de guerra civil (1828-1834), que pernoitaram no hospício dos Padres. Houve também encargos para o Convento, em comida e bebida, destinadas aos soldados e oficiais (Pereira, 2015, p. 226).

A degradação do Castelo vem a agravar-se devido a sucessivos abalos de terra, à extinção das Ordens Religiosas em 1834 e à morte da última religiosa, Soror Maria da Conceição de São José, em 1874. Deste momento em diante este espaço ficou, para além de desabitado, completamente abandonado tendo-se perdido algumas das estruturas fortificadas do castelo e muitos dos vestígios das estruturas que se erguiam no interior do seu recinto (Pereira, 2015, p. 227).

\section{ASPETOS GENÉRICOS SOBRE A ESCAVA- ÇÃO DO CONVENTO DE NOSSA SENHORA DE ARACOELI 1993-1995}

Caracterizada como uma intervenção de emergência, a escavação foi individualizada em três fases. A primeira incidiu sobre o espaço delimitado como convento, nomeadamente nas zonas do Coro Baixo - área H (torre 4), Corredor Norte-Sul/Deambulatório - área C, E, G, I, J, Refeitório - área B, Sala do Capítulo - área D, Claustro - área L e Igreja - área M. Já a segunda fase estendeu-se pela cerca conventual e a terceira reporta-se ao acompanhamento das obras de construção (Paixão; Faria, 1996, p. s. n.o.). Da referida primeira fase, destacam-se várias sondagens pelas zonas em questão de $2 \mathrm{~m}$ por $2 \mathrm{~m}$ e de $4 \mathrm{~m}$ por $4 \mathrm{~m}$, e que proporcionaram descobertas numerosas em termos de níveis de enterramento, através dos restos osteológicos e artefactos arqueológicos, como medalhas, contas de terço, entre outros e cerâmica, sobretudo dos séculos XVI ao XVIII. Não esquecendo todos os elementos construtivos como o esgoto, destinado ao escoamento das águas provenientes da cozinha, identificado na zona do refeitório e os vários troços de canalizações que transportavam a água pluvial recolhida no telhado do convento para a cisterna (localizada na parede sul), bem como para o pequeno tanque com repuxo, localizado no centro do Claustro (Paixão; Faria, 1996, p. s. n.o).

Na segunda fase, na zona da cerca, onde estavam implantados os acréscimos estruturais, que se estendiam para este e para norte das estruturas visíveis do edifício religioso, foram designados 14 quadrados de $9 \mathrm{~m}$ por $9 \mathrm{~m}$, os quais teriam a si atribuídas letras de $\mathrm{A} \mathrm{a} \mathrm{O}^{6}$ (Fig. 2). É desta zona, nomeadamente das áreas $\mathrm{B}$ e $\mathrm{H}$, que surgem as peças em estudo, uma vez que a partir destas se pretendia alargar o espetro formal examinado.

O sítio intervencionado apresentava uma reduzida potência estratigráfica, bem como um impressionante revolvimento de terras e sobreposição de construções (Gomes, 2008, p. 18; Barata, 2007, p. 12). Apesar de nos terem sido disponibilizados desenhos de cortes estratigráficos e registos fotográficos de planos e cortes das áreas em estudo 7 , foi-nos praticamente impossível conseguir acrescentar a este trabalho alguma interpretação dos níveis estratigráficos em que foram recolhidas as faianças portuguesas que aqui apresentamos. Neste aspeto, a ausência de cadernos de campos que nos pudessem propor-

\footnotetext{
6. Sendo que a área $\mathrm{L}$ corresponde excecionalmente à zona descoberta do Claustro.

7. Informação disponibilizada pela Dr. ․ㅡ Esmeralda Gomes.
} 
cionar esclarecimentos relativamente à ligação entre camadas, estruturas e material recolhido afetou substancialmente a concretização da interpretação arqueológica do sítio.

A Planta Geral das estruturas arqueológicas individualizadas por períodos (Fig. 2), divulgada pelo Gabinete de Arqueologia da CMAS, exibe nestas duas áreas um compartimento com estruturas identificadas atribuídas às Idades Média e Moderna, o qual se encontrava encostado à muralha do convento e que por falta de sustentação arqueológica não se confirma que tipo de utilização teria e se este poderia estar associado à deposição das faianças estudadas. No entanto, a observação de alguns dos desenhos de cortes estratigráficos destas áreas em associação com as fichas de sítio salientam as diferentes camadas, apesar de não se encontrarem atribuídas na totalidade das peças. $\mathrm{Na}$ área $\mathrm{H}$ surgem as camadas 1 e 2, sendo que a camada 1 surge maioritariamente relacionada a material disperso ou de superfície e a camada 2 surge associada a uma possível lixeira. Esta também é mencionada em certas fichas de sítio da área B, bem como, parcamente caracterizadas, as camadas 1,2 e 3.

A última fase apesar de ser indicada apenas como de acompanhamento focou-se no espaço do claustro, nas zonas a céu aberto e arcaria periférica, onde se evidenciaram paredes construídas nos séculos XIII e XIV, tal como mais níveis de enterramentos, estes datados na sua maioria dos séculos XVII a XVIII (Gomes; Ferreira, 2008, p. 10-11).

\section{O CONJUNTO DE FAIANÇAS DAS ÁREAS B E H DA CERCA CONVENTUAL}

Identificámos neste conjunto, correspondendo respetivamente à área $\mathrm{H} 338 \mathrm{NMI}$ num total de 1201 fragmentos, na área B 261 de 785 e no testemunho H/B 56 de 168 , perfazendo um total de 655 NMI e 2154 fragmentos de faiança portuguesa (Parreira, 2020, p. 48).

A análise formal e decorativa a partir de paralelos foi essencial neste trabalho, uma vez que as evidências arqueológicas apresentam-se pouco explícitas em relação ao contexto em que foram recolhidas. Numa primeira abordagem a este conjunto do acervo de material arqueológico recolhido no Convento de Nossa Senhora de Aracoeli, avançámos com conclusões que não podem deixar de ser parciais.

A maioria das formas de faiança recuperada corres- pondem aos denominados recipientes abertos, dos quais se reconheceram pratos de várias dimensões, rasos e fundos, covilhetes, taças, fruteira/travessa, bacia de degolada para sangria, escudelas e especieiro. Foram igualmente identificadas formas fechadas como púcaro, pote e garrafas ou frascos, variando em cada uma delas as dimensões. Outras formas como as pegas, asas, tampas e pequeno elemento de estatueta encontram-se identificadas neste conjunto. Tal como seria expectável, nesta coleção (Graf. 1) encontram-se melhor representados os pratos $(56,44 \%)$, seguindo-lhes as taças $(18,91 \%)$ e em menor número de exemplares identificados o púcaro, a degolada para sangria, o especieiro e o elemento de estatueta (o,23\%). Já os covilhetes, fruteira/travessa, escudelas, potes e tampas representam 2,13\% do conjunto, enquanto os fragmentos não identificáveis configuram um total de 21,44\% (Parreira, 202O, p. 50).

As decorações surgem sobretudo na superfície interior do fundo dos pratos e, por vezes nas superfícies interiores das abas, tal como nas paredes exteriores de covilhetes e taças. Apenas três fragmentos exibem decoração de amarelo e azul (o,17\%), 18 apresentam somente decoração de cor violeta (1,03\%), 219 não possuem pintura (12,59\%), enquanto $1018(58,51 \%)$ têm-na na cor de azul de cobalto e $482(27,70 \%)$ ostentam ornamentação que associa aquelas duas cores (Parreira, 202O, p. 65).

As ornamentações observadas podem subdividir-se, conforme os principais motivos que ostentam como antropomórficos, zoomórficos, heráldicos, inscrições, fitomórficos, geométricos e compósitos. Compondo esta última e a pretexto ilustrativo, contabilizamos os motivos das escamas, das três contas, das rendas, das volutas e dos aranhões (Tab.1) (Parreira, 2020, p. 65).

Deste modo, o conjunto arqueológico recuperado nas áreas B e H no Convento de Nossa Senhora de Aracoeli pode ser atribuível a um longo período, entre os finais do século XVI e os meados do século XVIII, mais precisamente produzida entre $1570 \mathrm{e}$ 1700/1766, de acordo com o acervo de faiança portuguesa ali recolhida (Parreira, 2020, p. 89).

\subsection{As marcas}

Apreciando o conjunto de faianças das áreas B e H do Convento de Nossa Senhora de Aracoeli, foram identificadas marcas que designamos como marcas incisas ou grafitos e dividimos em marcas alfabéticas e geométricas. Apresentamos também o número de 
marcas indeterminadas (3) pela sua relevância na totalidade do diminuto conjunto de faianças. Identificamos assim um total de 49 marcas, das quais 30 surgem em pratos, $15 \mathrm{em}$ taças e uma num covilhete, incidindo grande parte no tardoz das peças. No entanto, também se evidenciam estas marcas na base e no pé dos testemunhos cerâmicos (Tab. 2).

As marcas apresentam uma tendência alfabética (Graf. 2) mais demarcada, em relação às marcas geométricas (Graf.3). Neste âmbito, os grafitos alfabéticos exibem uma grande variedade de letras, as quais se encontram bastante percetíveis enquanto os motivos geométricos estão em número residual. Registaram-se as letras: $\mathrm{O}, \mathrm{P}$ (com elementos esféricos de distinção em torno), MI, F, S, U, G, N, H e h, E, I (com os mesmos elementos mencionados anteriormente), J, C e A (Fig. 4). Os motivos geométricos apresentam-se com os grafitos que se assemelham a: III, * e JL (Fig. 5).

Na sua grande maioria, estas peças apresentam marcas de desgaste, o que pode evidenciar que seriam usadas frequentemente. De notar que $48,79 \%$ das peças revelam marcas de desgaste tanto no bordo como no fundo. Evidenciam-se também em maior número nos fragmentos decorados, num total de 39 fragmentos, e em menor número, apenas 8 , nos que estão apenas revestidos a esmalte branco, nas áreas $\mathrm{B}, \mathrm{H}$ e testemunho $\mathrm{H} / \mathrm{B}$.

Por fim, estes são motivos incisos que se executavam com algum tipo de material afiado, como uma faca ou tesoura, e que seriam realizados depois da peça ser cozida, uma vez que o esmalte não cobre esta zona. Em alguns destes conseguimos ainda observar as zonas de incisão, onde este objeto afiado teria o seu primeiro contacto com a peça.

\section{DISCUSSÃO}

Identificaram-se paralelos no fundo ou tardoz de pratos e taças carenadas de faiança portuguesa provenientes do Convento de Jesus de Setúbal (Almeida; Fernandes; Cândido, 2016, p. 154) e da antiga prisão do Aljube em Lisboa (Amaro \& alii, 2016, p. 71, 75). Em Setúbal, particularmente, estes surgem em número residual no tardoz de duas taças hemisféricas e no fundo de um prato em ônfalo. Os grafitos de Lisboa possuem natureza alfabética, de cariz geométrico sendo identificados 24 exemplares, entre estes os de natureza alfabética mostram a forma da letra $\mathrm{V}$, $\mathrm{M}$ e X. Neste caso, a diferenciação feita entre as mar- cas aproxima-se de um significado muito próximo aos indivíduos que as produzem, como a inicial do nome próprio ou do apelido, tal como se regista para as marcas de canteiro de elementos arquitetónicos (Silvério, 2017, p. 1513).

Num âmbito ibérico, o estudo, de José Luiz Menéndez Fueyo, revela-se pertinente. Para este autor, o paradigma que se impõe é que estas marcas são por si sinais de História, testemunhos que representam um indivíduo ou mesmo um grupo a quem queremos minuciosamente compreender cada detalhe da sua vida. O elemento central no estudo de Menéndez Fueyo, proveniente da Basílica de Santa Maria de Alicante e correspondente a mais de 50 marcas incisas, o que supõe uma percentagem superior a $30 \%$ do total de peças com marcas e, que as converte num dos tipos de marcas principais localizados nos conjuntos recolhidos na igreja. Localizadas mais frequentemente na parte superior do corpo, de forma a estarem visíveis, em oposição ao conjunto presentemente estudado, estas surgem com uma enorme variedade de motivos, das quais se destacam as chamadas letras góticas, sobretudo o "b" e a estrela de cinco pontas (Menéndez Fueyo, 2012, p. 112).

Para o investigador valenciano a marca representa a propriedade, como um selo que garante a qualidade do produto (Menéndez Fueyo, 2012, p. 113). Considera também as marcas numerárias, que são as que mostram duas linhas verticais cruzadas por uma linha perpendicular e que podem corresponder a marcas de contabilidade (Menéndez Fueyo, 2012, p. 117). No conjunto do Convento de Nossa Senhora de Aracoeli, a semelhança que surge entre alguns dos grafitos de natureza alfabética (Graf. 2), tal como a sua repetição, sugere a utilização dessas peças pela mesma pessoa ou grupo socioeconómico dentro do ambiente clausural, nomeadamente freiras, noviças, padres, criadas, etc. (Almeida; Fernandes; Cândido, 2016, p. 154). Pelo menos a sua localização como é o caso da marca "S", no tardoz da caldeira de pratos, ou mesmo do "h", na mesma orientação, variando o tamanho, permite com alguma subjetividade afirmá-lo. Pressupõe-se ainda a associação de uma letra ou símbolo geométrico a uma pessoa sabendo mesmo que essa pode ter criado mais do que um símbolo para identificar o que lhe pertencia.

Neste âmbito, estes dados podem remeter-nos para as iniciais de algumas das freiras do convento, pois as letras incisas apresentam grande variabilidade entre si, como exemplo a letra $\mathrm{H}$ que surge em le- 
tra maiúscula e minúscula. Bem como o I, letra que tem dois pontos sobre si e outro que se encontra representado com quatro pontos à sua volta. Pode isto talvez significar que cada uma estaria associada a um indivíduo diferente com iniciais semelhantes, e que justificasse a necessidade desta distinção.

Qualquer hipótese que se exponha pode ser apresentada como viável, mas sempre subjetiva. Assim a necessidade de identificação individual dos conjuntos pode estar associada à consciencialização da individualização do consumo de alimentos que surge para controlo e proteção contra doenças contagiosas e epidemias (Almeida; Fernandes; Cândido, 2016, p. 154; Amaro \& alii, 2016, p. 70-71). No entanto, usando como exemplo uma taça do Convento de Jesus de Setúbal com a palavra Emferm ${ }^{a}$ (CJ o6 AVE Lix. XVII 11179 - Almeida, 2012, p. 444) a cursivo, esta pode indicar, para além de se relacionar com a Enfermaria, ainda, tal como Mendénez Fuyo refere, a importância de registar estas marcas em zonas visíveis da peça, uma vez que para alguém nesta condição ou numa peça de armazenamento talvez fosse efetivamente necessário algo que indicasse a sua exclusividade de utilização, para que se impedisse a propagação de doenças, ou mesmo para a indicação do tipo e capacidade de armazenamento dos contentores.

Neste sentido, as peças do conjunto que se analisou apresentam marcas em zonas ocultas. Pode isto significar que poderiam ser peças utilizadas à mesa e que identificariam um indivíduo ou uma utilização especial da peça para algum alimento? Estariam elas associadas ao uso exclusivo na preparação de alimentos ou seriam peças com qualquer outra utilização no quotidiano conventual?

Neste contexto, Joana Torres refere que apesar do carácter individual destes recipientes, nos séculos XVII e XVIII, não há uma preocupação, pelo menos em ambientes conventuais, em fazer marcas de posse, como muitas vezes sucedia em contextos medievais, sendo que estas marcas podiam surgir esporadicamente, para distinguir um objeto que fosse particular, tendo como propósito a sua identificação e não individualização (Torres, 2011, p. 87).

No conjunto que analisamos, a percentagem de fragmentos com grafitos inserida no total das áreas $\mathrm{B} \mathrm{e} \mathrm{H}$ é bastante diminuta $(2,27 \%)$. Mas a manifestação diversificada de letras que pudessem estar associadas a iniciais de indivíduos em contacto com o ambiente conventual, não poderá significar mais que uma simples identificação e assumir um carácter indivi- dualista? Os gráficos 2 e 3 podem ser justificativos disso mesmo, pois mostram a maior necessidade da utilização de letras e não símbolos, estas que podiam mais facilmente estar associadas ao nome próprio e individualizar a utilização de uma peça específica. No entanto, a corroboração deste estudo só pode ser justificada com a análise mais alargada de todo o conjunto cerâmico recolhido no contexto no Convento de Nossa Senhora de Aracoeli. Pretendemos somente, deste modo, dar a conhecer algumas destas marcas para que seja possível mais tarde, com o surgimento de novos elementos recolhidos em trabalhos arqueológicos, chegar cada vez mais próximo do verdadeiro significado destas.

\section{BIBLIOGRAFIA}

AHMALCS, CMALCS/CNSA/O2/o05, Pública Forma Transcrição da Escritura de doação da Herdade de Arapouco [3 Jun. 1573-7 Fev. 1857].

ALMEIDA, Mariana Brito (2012) - Convento de Jesus (Setúbal) Arqueologia e História: Faiança decorada. Lisboa: Dissertação de Mestrado apresentada à FCSH-UNL.

ALMEIDA, Mariana Brito; FERNANDES, Edgar; CÂNDIDO, Maria João (2016) - Portuguese Faience inspired by spanish forms in the Convento of Jesus of Setúbal ( $16^{\text {th }}$ and $\left.17^{\text {th }}\right)$. In GOMES, R. V.; CASIMIRO, Tânia; GOMES, M. V., eds. - Proceedings of the First Internacional Conference of Portuguese Faience ( $16^{\text {th }}-19^{\text {th }}$ Centuries). Lisboa: Instituto de Arqueologia e Paleociências, pp. 151-16o.

AMARO, Clementino; FILIPE, Vanessa; HENRIQUES, José Pedro; MANSO, Cláudia (2016) - Faiança quinhentista recuperada num compartimento da antiga prisão do Aljube, Lisboa. In GOMES, R. V.; CASIMIRO, Tânia; GOMES, M. V., eds. - Proceedings of the First Internacional Conference of Portuguese Faience ( $16^{\text {th }}-19^{\text {th }}$ Centuries). Lisboa: Instituto de Arqueologia e Paleociências, pp. 67-78.

ANDRADE, Maria (2011) - IN OBOEDIENTIA, SINE PROPRIO, ET IN CASTITATE, SUB CLAUSURA: A Ordem de Santa Clara em Portugal (Sécs. XIII - XIV). Lisboa: Dissertação de Doutoramento em História apresentada à FCSH-UNL.

ANTT, Província dos Algarves, Ordem dos Frades Menores, Alcácer do Sal/Aracoeli, Maço 1, № 54, Petição apresentada ao Príncipe Nosso Senhor para conceder licença para aceitar doze noviças [9 Set. 1792].

BARATA, Maria Filomena, coord. (2007) - Roteiro. Castelo de Alcácer do Sal: Cripta Arqueológica. Lisboa: Instituto de Gestão do Património Arquitetónico e Arqueológico.

CORREIA, Virgílio (1972) - Alcácer do Sal, esboço de uma monografia”. In Obras: Estudos Arqueológicos, Vol. 4. Coimbra: Acta Universitatis Coninbrigensis, pp. 127-155. 
GOMES, Esmeralda (2008) - Os ex-votos proto-históricos do Castelo de Alcácer do Sal. Lisboa: Tese de mestrado em Arqueologia apresentada à FL-UL.

GOMES, Esmeralda; FERREIRA, Marisol Aires (2008) Detalhes da vida privada no Convento de Aracaeli. In Alcácer do Sal: Terra de Deusas. Alcácer do Sal: CMAS, pp.7-14.

LEAL, Augusto Pinho (1873) - Alcácer do Sal. In Portugal Antigo e Moderno, Vol. I. Lisboa: Mattos Moreira \& Companhia, pp. 56-61.

LEITÃO, Marta Isabel Caetano (2015) - A Presença Islâmica em al-Qasr: Uma análise sobre o urbanismo e o sistema defensivo. Lisboa: Dissertação de Mestrado em Arqueologia apresentada à FCSH-UNL.

MENÉZES Fueyo, José Luís (2012) - Marcar la tinaja, firmar la historia. In La cerâmica medieval de la Basílica de Santa Maria de Alicante. Arqueología, arquitetura y cerâmica de una excavación arqueológica insólita en España. Oxford: Archaeopress (BAR Internacional Series; 2378), pp. 109-132.

NÓVOA, Rita Luís Sampaio da (2016) - O Arquivo Gama Lobo Salema e a produção, gestão e usos dos arquivos de família nobre nos séculos XV-XVI. Lisboa: Dissertação de Doutoramento apresentada à FCSH-UNL.

PAIXÃO, António Cavaleiro; FARIA, João Carlos (1996) Escavações arqueológicas no Convento de Nossa Senhora de Aracaeli (Alcácer do Sal): Relatório (Novembro de 1996). Alcácer do Sal: Câmara Municipal de Alcácer do Sal.

PARREIRA, Catarina Sofia Delgado (2020) - A Faiança Portuguesa do Convento de Nossa Senhora de Aracoeli (Alcácer do Sal). Lisboa: Dissertação de Mestrado em Arqueologia apresentada à FCSH-UNL.

PEREIRA, Maria Teresa Lopes (2015) - Os Cavaleiros D’Santiago em Alcácer do Sal (século XII a fins do século XV). Lisboa: Edições Colibri.

TORRES, Joana (2011) - Quotidianos no Convento de São Francisco de Lisboa: uma análise da cerâmica vidrada, faiança portuguesa e porcelana chinesa. Lisboa: Dissertação de Mestrado em Arqueologia apresentada à FCSH-UN.

SILVÉRIO, Sara (2017) - As Marcas de Canteiro da Sé de Lisboa. In Arnaud, J. M.; Martins, A. (eds.), Arqueologia em Portugal / 2017 - Estado da Questão. Lisboa: Associação dos Arqueólogos Portugueses, pp. 1513-1521. 

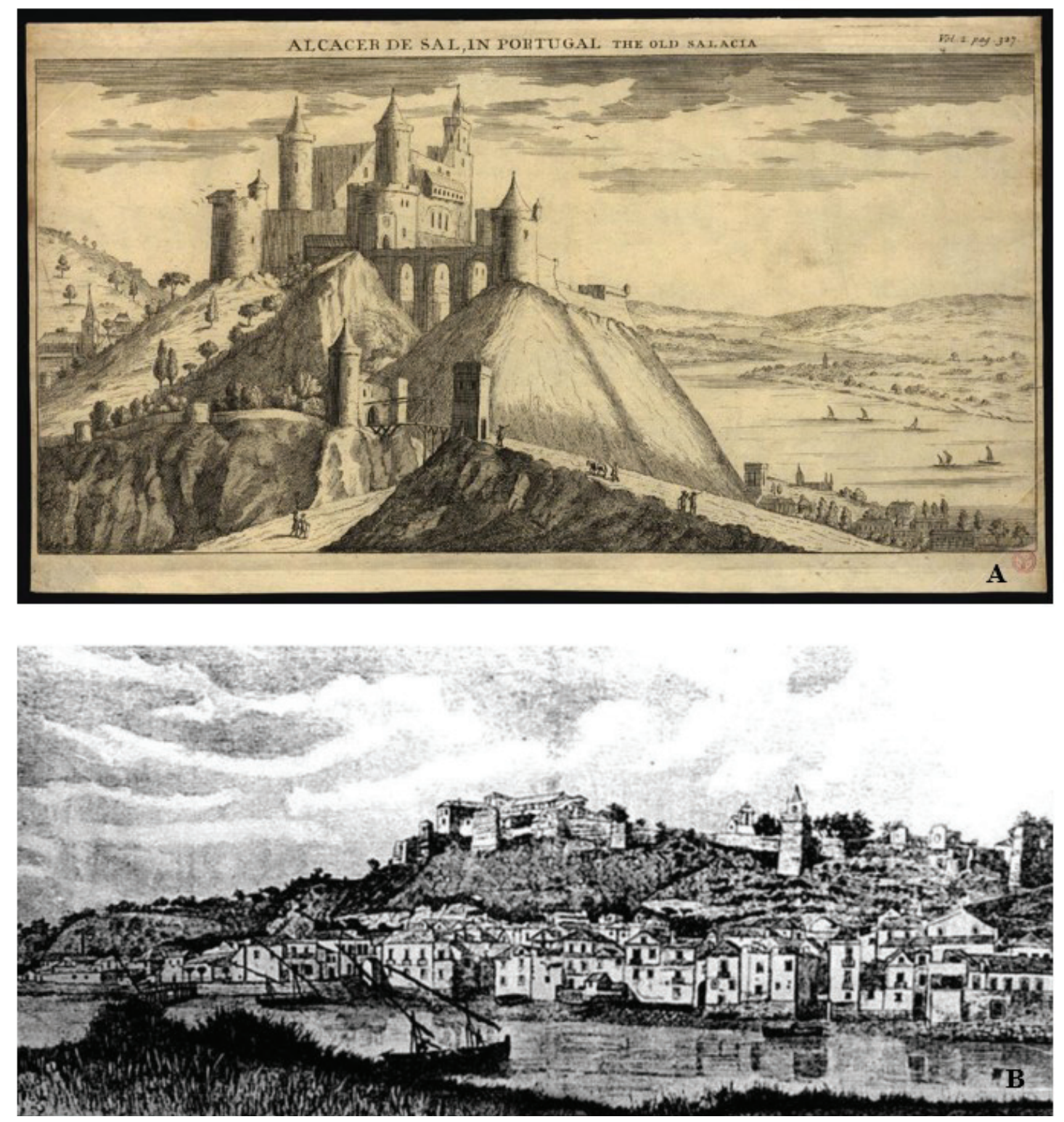

Figura 1 - A: Gravura fantasiosa da fortificação de Alcácer do Sal no século XVIII (Fonte: Biblioteca Nacional de Portugal - Autor desconhecido); B: Gravura de Alcácer do Sal, de 1889, onde se observa no topo do outeiro o Convento de Nossa Senhora de Aracoeli (Fonte: Arquivo do Museu Municipal de Alcácer do Sal - Autor Desconhecido). 

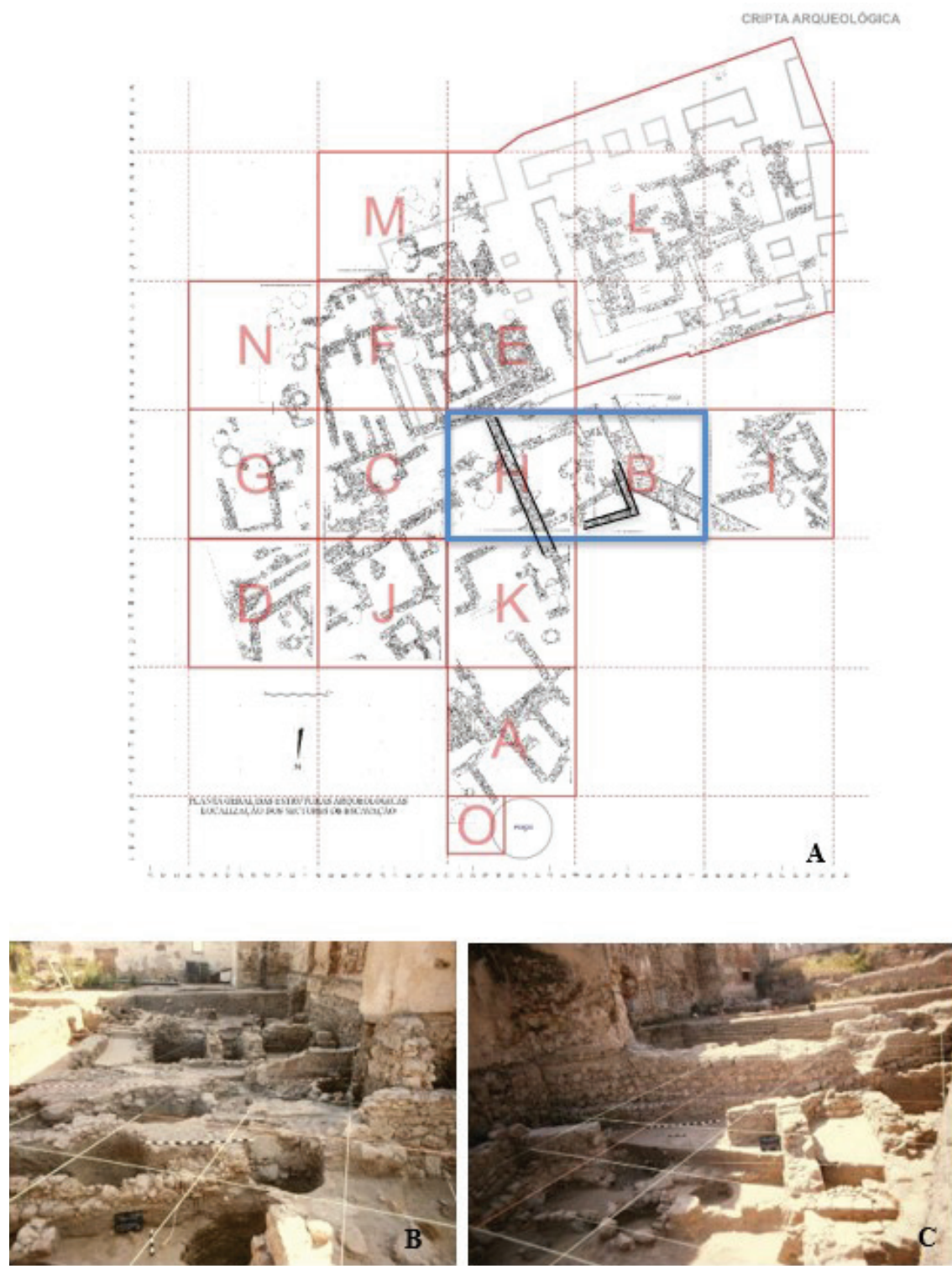

Figura 2 - A: Planta geral das estruturas arqueológicas e localização dos setores. Destaque a azul para os setores $\mathrm{H}$ e B e individualizadas a preto as estruturas da Idade Medieval/Moderna (cedida pelo Gabinete de Arqueologia de Alcácer do Sal); B: Vista geral das áreas H, B e E (fotografia de Manuel Perna cedida pela Câmara Municipal de Alcácer do Sal / Direção Regional de Cultura do Alentejo); C: Pano de muralha que fazia a divisão entre o convento e a cerca. Visíveis as estruturas da área B e H (fotografia de Manuel Perna cedida pela Câmara Municipal de Alcácer do Sal / Direção Regional de Cultura do Alentejo). 


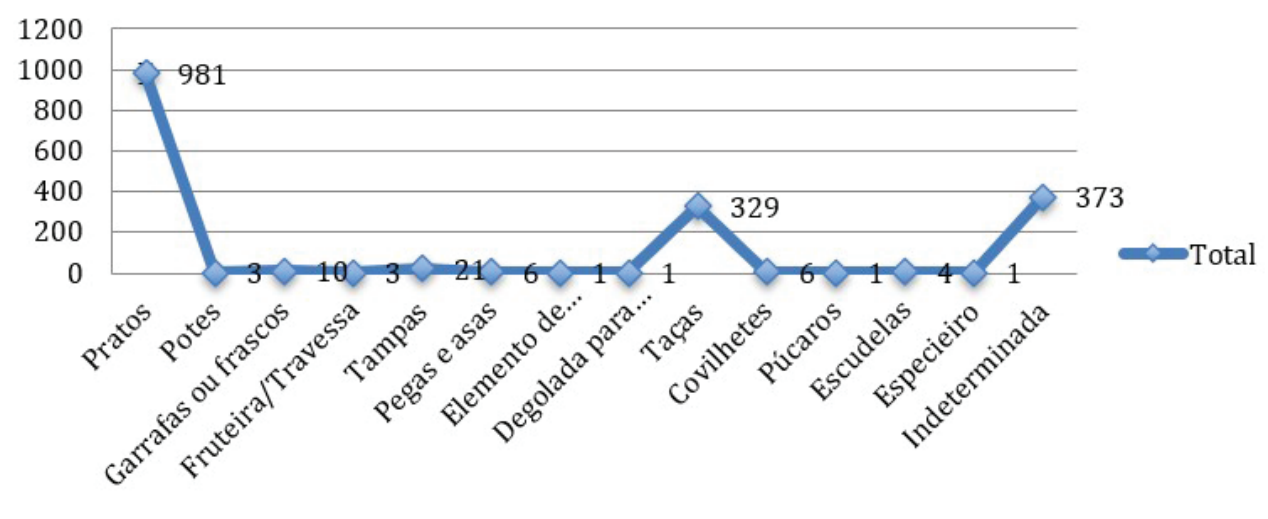

Gráfico 1 - Formas presentes na coleção das áreas B e H da cerca do Convento de Nossa Senhora de Aracoeli, por número fragmentos.

\begin{tabular}{|c|c|c|c|c|c|c|c|c|c|c|c|c|c|c|c|c|c|c|c|c|c|c|c|c|c|c|}
\hline \multirow[t]{3}{*}{ Formas } & \multicolumn{25}{|c|}{ Motivos decorativos } & \multirow{3}{*}{ Total } \\
\hline & \multicolumn{4}{|c|}{ Antrop. } & \multicolumn{3}{|c|}{ Zoom. } & \multicolumn{4}{|c|}{ Heráldicos } & \multicolumn{3}{|c|}{ Inscrições } & \multicolumn{4}{|c|}{ Fitomórfico } & \multicolumn{3}{|c|}{ Geométricos } & \multicolumn{4}{|c|}{ Compósitos } & \\
\hline & $\mathrm{v}$ & \begin{tabular}{l|l}
$\mathrm{A}$ & $\mathrm{I}$ \\
\end{tabular} & VA & AA & \begin{tabular}{l|l}
$\mathrm{V}$ & $\mathrm{A}$ \\
\end{tabular} & \begin{tabular}{|l|l|} 
& $V A$ \\
\end{tabular} & AA & $\mathrm{v}$ & \begin{tabular}{l|l}
$\mathrm{A}$ & $\mathrm{V}$ \\
\end{tabular} & \begin{tabular}{l|l}
$\mathrm{A}$ & $\mathrm{A}$ \\
\end{tabular} & \begin{tabular}{l|l}
$A A$ & $V$ \\
\end{tabular} & \begin{tabular}{l|l|}
$\mathrm{V}$ & $\mathrm{A}$ \\
\end{tabular} & VA & AA & $\mathrm{v}$ & $\mathrm{A}$ & $\mathrm{VA}$. & $\mathrm{AA}$ & \begin{tabular}{l|l}
$\mathrm{V}$ & $\mathrm{A}$ \\
\end{tabular} & \begin{tabular}{l|l}
$\mathrm{A}$ & $\mathrm{V}$ \\
\end{tabular} & \begin{tabular}{l|l|}
$\mathrm{A}$ & $\mathrm{AA}$ \\
\end{tabular} & \begin{tabular}{l|l|}
$A$ & $V$ \\
\end{tabular} & \begin{tabular}{|l|l|} 
& $\mathrm{A}$ \\
\end{tabular} & VA & AA & \\
\hline Pratos & & 2 & 1 & & 3 & \begin{tabular}{l|l|}
3 & 1 \\
\end{tabular} & & & \begin{tabular}{l|l}
26 & 1 \\
1
\end{tabular} & 16 & & \begin{tabular}{|l|l|}
2 & 8 \\
\end{tabular} & 5 & & 2 & 118 & 25 & & & \begin{tabular}{l|l}
53 & 2 \\
\end{tabular} & 2 & & 131 & 230 & & 725 \\
\hline Potes & & & & & & & & & & & & & & & & 2 & & & & & & & & 1 & & 3 \\
\hline $\begin{array}{l}\text { Garrafas ou } \\
\text { frascos }\end{array}$ & & & & & & & & & & & & & & & & 2 & 1 & & & 3 & & & & & & 6 \\
\hline Fruteiras/travessas & & & & & & & & & & & & & & & & & & & & 2 & & & & & & 2 \\
\hline Tampas & & & & & & & & & & & & & 2 & & & 2 & 2 & & \begin{tabular}{l|l}
2 & 1 \\
\end{tabular} & 1 & 1 & 1 & 1 & 5 & & 16 \\
\hline Pegas e asas & & & & & & & & & & & & & & & & & & & & & & & 1 & & & 1 \\
\hline $\begin{array}{l}\text { Degolada para } \\
\text { sangria }\end{array}$ & & & & & & & & & & & & & & & & 1 & & & & & & & & & & 1 \\
\hline Taças & & & & & & & & & & & & 1 & 2 & & \begin{tabular}{|c|}
5 \\
\end{tabular} & 21 & 1 & & & \begin{tabular}{l|l}
53 & 1 \\
\end{tabular} & 1 & & 37 & 77 & & 198 \\
\hline Covilhetes & & & & & & & & & & & & & & & 1 & & & & & 1 & & & 1 & 2 & & 5 \\
\hline Púcaros & & & & & & & & & & & & & & & & 1 & & & & & & & & & & 1 \\
\hline Escudelas & & & & & & & & & & & & & & & & & & 1 & & & & & & 1 & & 2 \\
\hline Indeterminadas & & & & & 1 & & & \begin{tabular}{l|l} 
\\
\end{tabular} & 4 & & & \begin{tabular}{l|l|}
1 & 1 \\
\end{tabular} & 1 & & & 18 & 7 & & \begin{tabular}{l|l}
1 & 19 \\
\end{tabular} & 19 & & & 22 & 51 & & 127 \\
\hline Total & & 2 & 1 & & 4 & \begin{tabular}{l|l|}
4 & 1 \\
\end{tabular} & & \begin{tabular}{l|l}
1 & 3 \\
\end{tabular} & \begin{tabular}{l|l}
30 & 1 \\
\end{tabular} & 16 & & \begin{tabular}{|l|l|}
3 & 10 \\
\end{tabular} & 10 & & 8 & 165 & 36 & 1 & \begin{tabular}{l|l}
3 & 23 \\
\end{tabular} & \begin{tabular}{l|l}
32 & 3 \\
32 & $x$
\end{tabular} & 1 & 1 & 193 & 367 & & 1087 \\
\hline
\end{tabular}

Tabela 1 - Formas e cores das decorações da faiança das áreas B e H da cerca do Convento de Nossa Senhora de Aracoeli (V = Violeta; A = Azul; VA = Violeta e Azul; AA = Azul e amarelo), por número de fragmentos. Não se incluem as peças sem pintura.

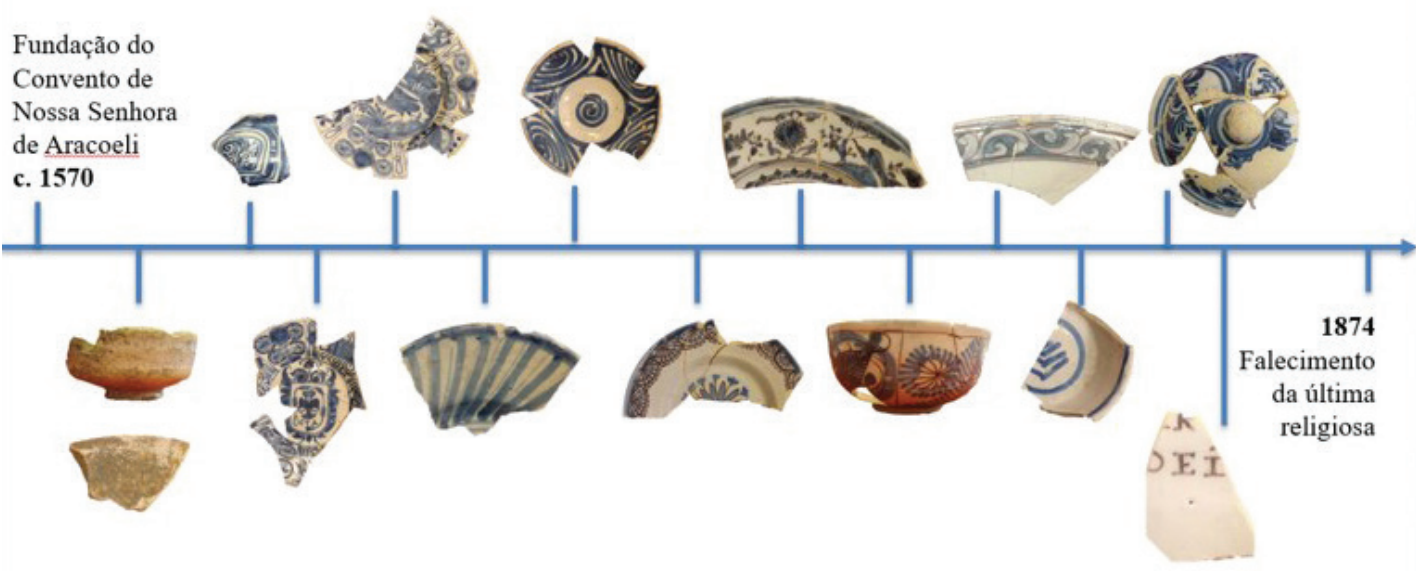

Figura 3 - Conjunto arqueológico, que pode ser atribuível a um longo período, entre os finais do século XVI e os meados do século XVIII (1570-1700/1766). Autor: Catarina Parreira. 


\begin{tabular}{|c|c|c|c|c|c|c|c|c|c|}
\hline \multirow{2}{*}{ Marcas } & \multicolumn{3}{|c|}{ Formas } & \multicolumn{2}{c|}{$\begin{array}{c}\text { Marcas de } \\
\text { desgaste }\end{array}$} & \multicolumn{2}{c|}{ Zona de incisão } \\
\hline & Pratos & Taças & Covilhetes & Ind. & C/m & S/m & Base & Tardoz & Pé \\
\hline Geométricas & 5 & - & - & - & 5 & 1 & 1 & 4 & 1 \\
\hline Alfabéticas & 15 & 8 & 1 & - & 18 & 6 & 8 & 16 & - \\
\hline Indeterminadas & 10 & 7 & - & 3 & 11 & 9 & 3 & 14 & - \\
\hline Total & 30 & 15 & 1 & 3 & 34 & 16 & 12 & 34 & 1 \\
\hline
\end{tabular}

Tabela 2 -Incidência de marcas geométricas e alfabéticas na faiança do Convento de Nossa Senhora de Aracoeli (Ind. = Indeterminado; $\mathrm{C} / \mathrm{m}=\mathrm{Com}$ marca; $\mathrm{S} / \mathrm{m}=$ Sem marca), por número de fragmentos.

Marcas Alfabéticas

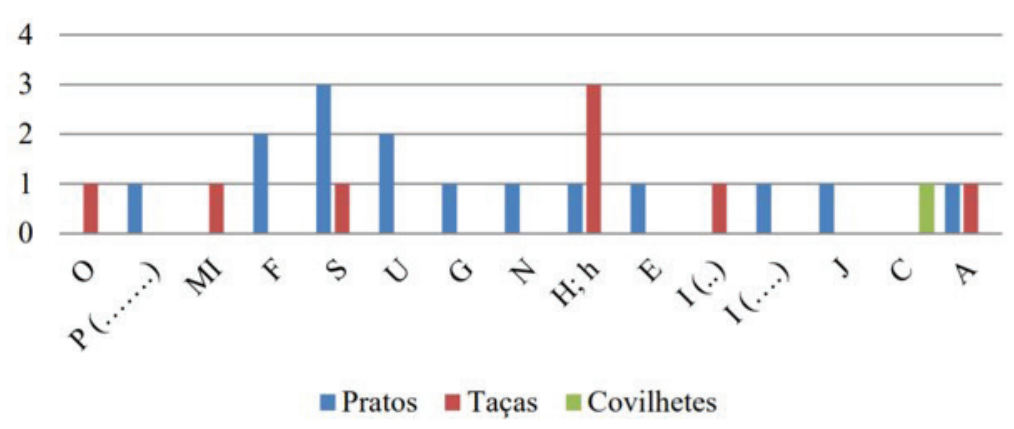

Gráfico 2 - Total de marcas alfabéticas distribuídas por formas (pratos; taças e covilhetes), por número de fragmentos.

\section{Marcas Geométricas}

4

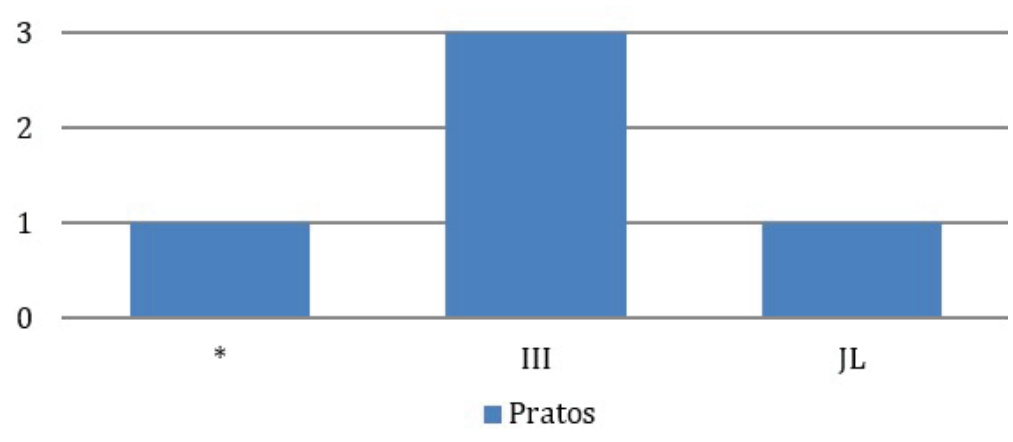

Gráfico 3 - Total de marcas geométricas identificadas exclusivamente em pratos, por número de fragmentos. 

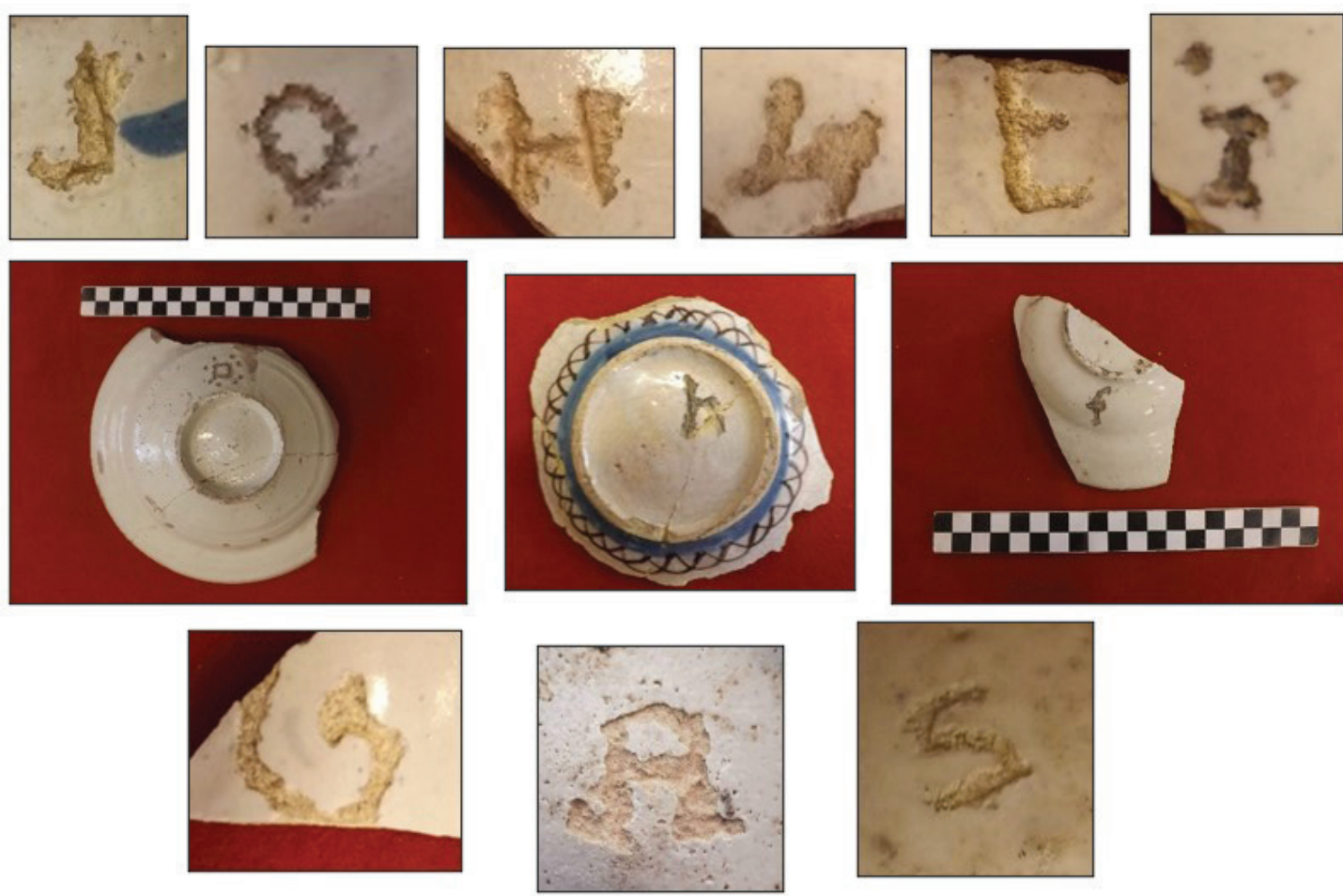

Figura 4 - Exemplares de marcas alfabéticas. Autor: Catarina Parreira.
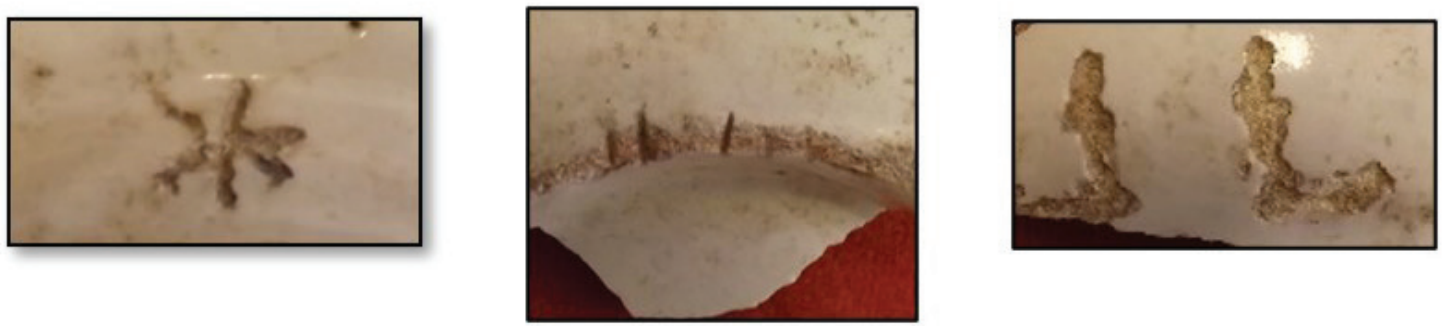

Figura 5 - Exemplares de marcas geométricas. Autor: Catarina Parreira. 



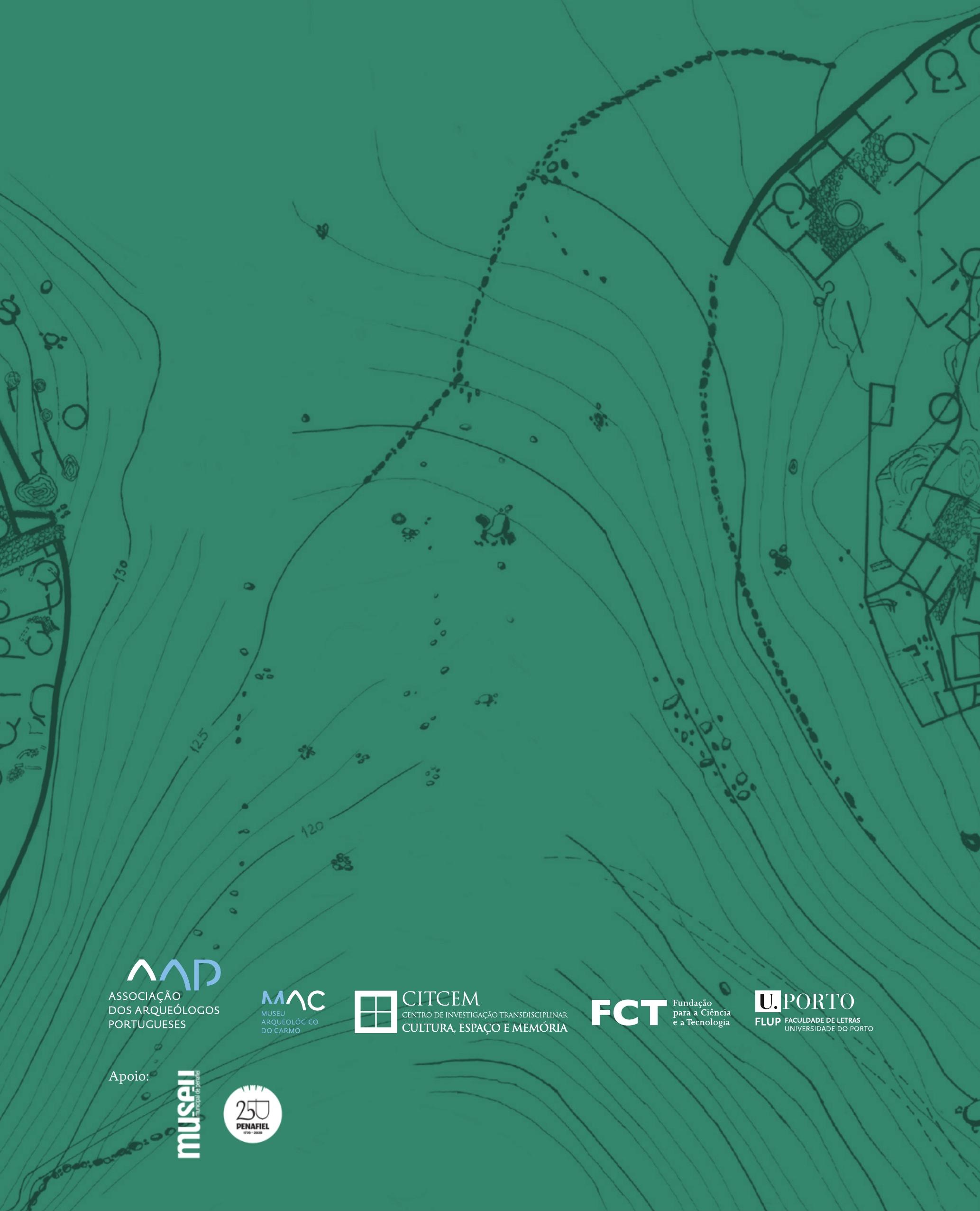

